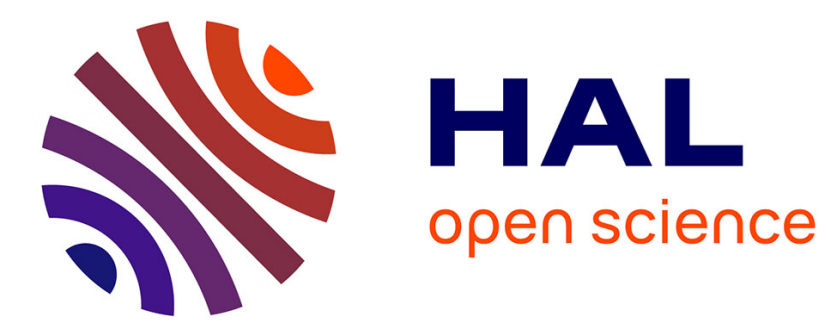

\title{
Reference Groups and Variable Risk Strategies
}

Thorbjørn Knudsen

\section{To cite this version:}

Thorbjørn Knudsen. Reference Groups and Variable Risk Strategies. Journal of Economic Behavior and Organization, 2008, 66 (1), pp.22. 10.1016/j.jebo.2007.02.004 . hal-00579786

\section{HAL Id: hal-00579786 \\ https://hal.science/hal-00579786}

Submitted on 25 Mar 2011

HAL is a multi-disciplinary open access archive for the deposit and dissemination of scientific research documents, whether they are published or not. The documents may come from teaching and research institutions in France or abroad, or from public or private research centers.
L'archive ouverte pluridisciplinaire HAL, est destinée au dépôt et à la diffusion de documents scientifiques de niveau recherche, publiés ou non, émanant des établissements d'enseignement et de recherche français ou étrangers, des laboratoires publics ou privés. 


\section{Accepted Manuscript}

Title: Reference Groups and Variable Risk Strategies

Author: Thorbjørn Knudsen

PII:

DOI:

S0167-2681(08)00026-7

Reference: doi:10.1016/j.jebo.2007.02.004

JEBO 2166

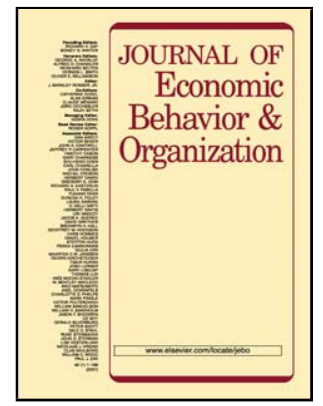

To appear in:

Journal of Economic

Behavio

\& Organization

Received date: $\quad 1-6-2003$

Revised date: 1-6-2005

Accepted date: $\quad 1-2-2007$

Please cite this article as: Knudsen, T., Reference Groups and Variable Risk Strategies, Journal of Economic Behavior and Organization (2007), doi:10.1016/j.jebo.2007.02.004

This is a PDF file of an unedited manuscript that has been accepted for publication. As a service to our customers we are providing this early version of the manuscript. The manuscript will undergo copyediting, typesetting, and review of the resulting proof before it is published in its final form. Please note that during the production process errors may be discovered which could affect the content, and all legal disclaimers that apply to the journal pertain. 


\title{
Reference Groups and Variable Risk Strategies*
}

\author{
By \\ Thorbjørn Knudsen \\ Strategic Organization Design Unit (SOD), \\ Department of Marketing \& Management, \\ University of Southern Denmark, \\ Campusvej 55, DK-5230 Odense M, Denmark \\ Email: tok@sam.sdu.dk
}

2 February 2007

\begin{abstract}
The present article examines two important effects that have been given scant attention in prior studies of variable risk strategies. The first effect, reference group sensitivity, is the degree to which decision makers' aspirations are sensitive to their reference group. In this paper we compare the performances of decision makers with alternative levels of reference group sensitivity. Second, we introduce the novel concept of community effect. This relates to mobility among multiple segregated reference groups. The performance of decision makers residing in a world with one single population is compared with that of decision makers who have the possibility, which is more or less costly, to switch between multiple populations. The results support the findings from previous studies that variable risk strategies are preferred over fixed risk. The study of a community of populations provides additional insights that both support and complement previous research.
\end{abstract}

Keywords: Adaptive aspirations, Variable risk, Reference groups, Community effect, Learning, Decision making

\footnotetext{
*The author wishes to thank the editor, an anonymous reviewer, Markus C. Becker, Henrich Greve, Tage Koed Madsen, James G. March, Nils Stieglitz, participants of the Academy of Management meetings, and the Strategic Organization Design (SOD) seminar at the University of Southern Denmark for stimulating and helpful comments.
} 


\section{Reference Groups and Variable Risk Strategies}

The concept of aspiration level has stimulated important insights relating to variable risk strategies used in actual practice. We now have a good understanding of the effects associated with aspiration adjustments by individual decision makers. However, in terms of aspiration level adjustments relating to reference groups, there is a significant gap in our knowledge. The contribution of this paper is to address this gap by providing a systematic examination of the reference group context as a basis for variable risk strategies. This topic relates to classical treatments of referent choice (Festinger 1954, Thibaut and Kelley 1959, Schumpeter 1934) as well as more recent important studies on social influences that impinge on individual decision making, including the effect of relative income comparisons (Frey and Stutzer 2002) and social interaction (Posch et al. 1999). Considering reference groups in the context of adaptive aspiration levels and variable risk strategies provides a useful extension to prior work on the behavioural theory of the firm (Herriott et al. 1985, March 1988, March and Shapira 1987). ${ }^{1}$

The concept of aspiration level has become the core construct in behavioural theory of the firm. This concept emerged in social psychology in the 1930s (Lewin 1939, Lewin et al. 1944), ${ }^{2}$ and in the post-war period quickly gained remarkable and widespread popularity throughout the social sciences (see Appendix 1). In most disciplines, including economics, education, political science, and sociology, the use of the concept of aspiration level peaked in the 1970s, or earlier. ${ }^{3}$ The $^{2}$ exception is business studies where aspiration level continued to be popular as a concept throughout the 1990s. Perhaps this development reflects a virtue of the behavioural theory of decision making in that it models the dynamic adjustment of goals that can be observed in the real organizations that are studied in the management, marketing and organization literatures (Greve 1998, Lant 1992, West and Broniarczyk 1998).

It is interesting to examine why use of the concept of aspiration level generally declined after the 1970s. While a more systematic analysis of this question is outside the scope of the present article, a possible economics explanation is that an epidemiological spread of the rational

\footnotetext{
${ }^{1}$ Augier and Kreiner (2000) provide useful background material on the behavioural perspective.

${ }^{2}$ Clawson (1950) has a nice summary of Kurt Lewin's work on aspiration levels.

${ }^{3}$ Measured by the absolute number of published articles, a J-STOR search shows that use of the concept of aspiration level peaked in the 1970s in economics, education, political science, and sociology (Figure 2, Appendix 1). However, if we control for number of journals in each field, the picture changes (Figure 3, Appendix 1). In this case, use of this concept in education and sociology peaked in the latter part of the 1950s, while in economics, political science and business studies it peaked in the mid-1970s. There is also indication of more widespread use of the term in business studies throughout the 1990s.
} 
expectations model crowded out the aspiration model. It is also interesting, here, to note an apparent re-emergence of the concept of aspiration level associated with the study of reinforcement learning in experimental economics and analogous behavioural processes in game theory. This development is associated with calls for a more solid behavioural grounding of learning processes and other important social phenomena. There is plenty of evidence supporting this proposition (Binmore and Samuelson 1997, Björnerstedt and Weibull 1996, Borgers and Sarin 2000, Gale et al. 1995, Posch 1999, Posch et al. 1999, Schlag 1998, Weibull 2002). ${ }^{4}$

By focusing on the behavioural grounding of actual learning processes, aspiration level research also relates to notable violations of game theoretic and other rationality principles observed in many empirical studies of decision making (Berg 1974, Kagel and Roth 1995, Kahneman and Tversky 1979, Payne et al. 1980, 1981, 1984). ${ }^{5}$ A further recent application of the concept of aspiration level is found in economic research on happiness (Frey and Stutzer). In this line of work, the concept of aspiration level captures phenomena relating to relative income and thus extends to the context of reference groups, which is the main focus of the present article.

According to the behavioural theory of the firm, the concept of aspiration level allows decision makers to cope with their cognitive limitations by adapting their aspirations to reflect personal histories. ${ }^{6}$ Decision makers' actual cognitive limits usually prevent a unique maximal level of achievement from being identified, and sometimes the situation is so messy that such maximal levels do not exist. Accordingly, decision makers need to develop adaptive strategies in order to cope with their limitations. The role of adaptive levels of aspirations is to provide convenient single-valued summaries of past achievements. Adaptive aspirations therefore provide a good basis for the level of achievement a decision maker can hope to realise within a particular context.

Previous adaptive aspiration models have helped to explain the relation between adaptive aspirations and variable risk strategies, and why decision makers generally can benefit from variable risk strategies (Herriott et al. 1985, March 1988, March and Shapira 1987). The purpose of the present article is to examine the relation between adaptive aspirations and variable risk strategies in more detail, in order to better understand the reference group context as a basis for

\footnotetext{
${ }^{4}$ See, for example, Reinhard Selten's work dating back to the 1960s. Interestingly, some of these studies contain no apparent trace as regards the prior use of the concept of the aspiration level in the behavioural theory of the firm.

${ }^{5}$ Weibull (2002) finds that the frequent claim that human subjects in the laboratory violate game theoretic rationality principles is premature because the subjects' preferences are usually not identified in empirical studies. Luce and von Winterfeldt (1994) consider violations of subjective expected utility, often reported in the empirical literature.

${ }^{6}$ Important early works include Cyert and March (1956, 1963), Cyert et al. (1958), March and Simon (1958), Simon (1955, 1956). Key works published in the 1980s include Herriott et al. (1985), Levinthal and March (1981), March (1988), and March and Shapira (1987).
} 
variable risk strategies. Two effects are examined that are ultimately found to be important determinants of the efficacy of variable risk preferences.

The first effect, referred to as reference group sensitivity, has been considered in previous works (Herriott et al. 1985, March 1988, March and Shapira 1987), but it has not been explored in great detail. Reference group sensitivity is defined here as the degree to which decision makers' aspirations adapt to the average wealth of the population in which they are currently located. It is termed reference group sensitivity because it tracks the wealth of others in the decision maker's own population. Obvious examples are managers who find it useful to benchmark against other firms or teenagers who are sensitive to the tastes of their peers.

The second effect is an extension of existing aspiration level models that consider a community of populations. The community effect is a novelty introduced in the present article. Decision makers located in any of a number of populations consider whether any of the other populations is doing better. The decision maker moves if the average cumulated wealth in any other population is higher, net of possible switching costs, but otherwise stays put. In order to examine the community effect, alternative numbers of populations are studied. The community effect seems to be present in many kinds of social dynamics, including entry at higher levels of the academic ladder. New PhD students, assistant professors, and so on may accept the mean performance of their more seasoned peers as a level of aspiration. To the extent that they focus on an upward moving target, they will tend to be rather risk prone. It is a process where newcomers tend to be useful waste in an evolutionary process that stimulates continuous increases in performance; new entrants most often will fail, but on rare occasions will realize spectacular careers. With similar consequences, firms that enter a high performing industry may accept the performance of its new peers as a worthy referent target.

The present article builds on what have now become standard references in aspiration level research (Herriott et al. 1985, Levinthal and March 1981, March 1988 and 1996, March and Shapira 1987 and 1992). The simulation approach adopted is similar to previous studies, but includes examination of previously unexplored parameters. The particular model studied here is an extension of March's (1988) model in which a decision maker's risk preferences is a function of current resources relative to an aspiration level. The model developed by March (1988) uses a convex function of wealth and performance to update aspirations, and the updating rule is stochastic because the wealth component is drawn from a normal distribution. This model convincingly showed that endogenous, varying risk preferences dominated fixed risk preferences. 
Our model, which includes both reference group sensitivity and a community of populations, is referred to as the community model. The community model provides more detailed insight into the reference group context as a basis for adapting aspirations: (1) by comparing the performances of decision makers endowed with alternative levels of reference group sensitivity, and (2) by comparing the performances of decision makers living in a world of one single population with that of decision makers living in a world where it is possible, but more or less costly, to switch between multiple populations.

The article is organized as follows. The first section below briefly introduces March's (1988) standard model, which is used as a baseline. The second section introduces the extensions of the standard model relating to single and multiple reference groups. The third section describes the detail of the simulation. The simulation results are presented in the fourth section (for a single population) and in the fifth section (for multiple populations). The sixth section considers in more detail the results obtained in order to understand why the reference group model dominates the standard model and why the community effect relating to multiple reference groups further emphasizes this dominance. The seventh section concludes the article.

\section{The Standard Model}

The present article extends the effects considered in the standard references for aspiration level research (Herriott et al. 1985, Levinthal and March 1981, March 1988 and 1996, March and Shapira 1987and 1992). In particular, March's (1988) model, in which a decision maker's risk preference is a function of current resources relative to an aspiration level, serves as a baseline model and is referred to as the standard model.

In statistical terminology the standard model is a sequential sampling random walk with an absorbing barrier at zero cumulated wealth. The standard model employs $N$ decision makers who are born with a stake $W_{i, 0}$, and according to their luck in a game against nature, increase or decrease their initial stake. In each period, each decision maker receives a pay-off that will add to or reduce her cumulated wealth. The population of decision makers is constant. If the cumulated wealth of a decision maker should reach zero, that unfortunate individual is bankrupt and will immediately be replaced by a new decision maker who enters the play with an initial stake $W_{i, 0}$. The pay-off is determined by a draw from a normal distribution with expectation 0 and standard deviation $R_{i, t}$, the 
preference for risk. Decision maker $i$ will adjust $R_{i, t}$ at time $t$, according to the following specification,

$$
R_{i, t}=\beta A_{i, t} / W_{i, t}
$$

$A_{i, t}$ is the aspiration level or target of decision maker $i$, and $W_{i, t}$ is the cumulated wealth of this decision maker at time $t$. The parameter $\beta$ is a scale factor for risk that is set to 1 in all the models in the present article. Each decision maker, $i$, comes to the simulation with the initial stake $W_{i, 0}$ and an initial aspiration level $A_{i, 0}=W_{i, 0}$, so the initial preference for risk $R_{i, 0}$ is 1 . The decision maker's level of aspiration adapts according to the following standard function of convex updating:

$$
A_{i, t+1}=\alpha W_{i, t}+(1-\alpha) A_{i, t}
$$

The weight $\alpha$, given to cumulated wealth, is bounded in the closed interval [0,1]. In the case that $\alpha$ $=0$, the aspiration level does not change; it is fixed at the initial value $\mathrm{A}_{\mathrm{i}, 0}$ given to decision maker $i$ at birth. When $\alpha=1$, the aspiration level adapts instantaneously to $\mathrm{W}_{\mathrm{i}, \mathrm{t}}$, since $\alpha$ determines the rate at which aspirations adapt to cumulative wealth, it is referred to as the rate of aspiration adjustment.

\section{The Community Model}

Previous studies (Herriott et al. 1985, March and Shapira 1987) have proposed an extension to the standard model in which the aspiration level of each risk taker may depend on the resources $W_{j, t}{ }_{j, t}$ accumulated by others,

$$
A_{i, t+1}=\alpha \psi W_{j, t}^{\prime}+\alpha(1-\psi) W_{i, t}+(1-\alpha) A_{i, t}
$$

The weight $\psi$, given to the wealth accumulated by others in the decision maker's own population $j$, is bounded in the closed interval $[0,1]$. We refer to it here as reference group sensitivity because it tracks the wealth of other members of the population in which the decision maker is currently located. When $\psi=0$, no weight is given to the wealth of others, and the model becomes the standard 
aspiration updating function (Equation 2). When $\psi=1$, all weight is assigned to the wealth of others.

$W_{j, t}^{\prime}$ may be a particular group, $j$, of others, for example, others who do better (March and Shapira 1987). In our simulation, decision makers assign weight to the average wealth (including self) accumulated by $N_{j}$ decision makers in the population $j$ in which they are located:

$$
W_{j, t}^{\prime}=\Sigma W_{i, t} / N_{j}
$$

This extension of the aspiration level model considers only one population. A further extension, the community model, considers $M$ multiple populations. With probability $1 / M$ a decision maker is initially assigned to one out of the $M$ populations. Decision makers located in each of the $M$ populations may consider whether any of the other populations, on average, do better. The decision maker moves if the average cumulated wealth in any other population, $W_{-j, t,}^{\prime}$, is higher, net of the possible costs of switching, $\delta$. Otherwise, the decision maker stays. That is, the decision maker moves if

$$
W_{j, t}^{\prime}<W_{-j, t}^{,}-\delta
$$

Since a decision maker's move between two populations will alter the average wealth in both, each time step treats the decision makers in random order.

The purpose of the community model is to compare the performance of decision makers that ignore others with that of decision makers who are sensitive to the population in which they are currently located and to the wider context of other populations. The next section reports the results of the community model. 


\section{The Simulation}

The simulation in the present paper is similar to the approach taken in previous studies (Levinthal and March 1981, March 1988, March and Shapira 1987); it differs in examining previously unexplored parameters. In the present study, alternative levels of four parameters are examined: (1) the rate of aspiration adjustment $\alpha(0.10,0.50,1.00) ;(2)$ the reference group sensitivity $\psi(0.00$, $0.10,0.50,1.00)$; (3) the switching cost $\delta(0.10,0.50,1.00)$; and (4) the number of possible populations $M(2,5,10)$. The number $M$ is the maximum number of possible populations, but depending on the switching costs, the actual number of populations may be lower.

The simulation reported here examines a total of 144 distinct combinations of the four parameters $(\alpha, \psi, \delta$, and $M)$. The 144 combinations of parameter values provide an exhaustive description of the parameter space in the sense that they include the outcomes in which cumulated wealth and survival are maximized. This conclusion was arrived at through multiple scans of the parameter space. For each of the 144 combinations of the parameter values, 30 samples were obtained for a population of 300 decision makers. Each sample obtained the cumulated ruin rates and wealth of the population for $T=10,000$ time periods.

Given the values of the four parameters $\alpha, \psi, \delta$, and $M$, the only remaining free parameter, the initial stake $W_{i, 0}$, was set to 3 as in March's (1988) standard model. This value of $W_{i, 0}$, ensures that the probability of losing the initial stake in the first draw is very low $(\mathrm{p}=0.004)$. In order to avoid absurdly high values of $R_{i, t}$, the absorbing barrier was set to 0.1 . That is to say, if a decision maker's cumulated wealth, $W_{i, t}$, reaches 0.1 , he or she is replaced by a new decision maker.

Figure 1 shows the relation between the ruin rate of decision makers and the cumulated wealth of the surviving population over 10,000 time periods. March's (1988) standard model was used as a baseline model. The values obtained for the standard model in the present study were based on averages of 30 samples for each of the three levels of the rate of aspiration adjustment $(\alpha=0.10$, $0.50,1.00$ ) examined (a total of 90 samples). These values are similar to those reported in March (1988).

Each panel compares the standard model with averages of the values obtained for the community model with maximal reference group sensitivity $(\psi=1.00)$ and one level of switching 
costs. ${ }^{7}$ In each panel, the values obtained for the community model were based on averages of 30 samples for each of the 9 combinations of $\alpha$ and $M$ (a total of 270 samples).

\section{Results for One Population}

The first panel in Figure 1 shows the relation between ruin rate and cumulated wealth for maximal reference group sensitivity $(\psi=1.00)$ and zero switching costs $(\delta=0.00)$. In the case of zero switching costs, all population members in the community model will be located in one place. In this case, the only difference between the standard model and the community model is the sensitivity to the wealth of others. The results for the community model, shown in the first panel of Figure 1, are averages for $\psi=1.00$.

As can be seen from the first panel in Figure 1, the community model dominates the standard model when decision makers have complete sensitivity to the average wealth of others. For any value of the number of time steps, $T$, complete sensitivity to the average wealth of the population $(\psi=1.00)$, and thus ignorance of own wealth, leads to both higher average cumulated wealth and lower ruin rates than does ignorance of others $(\psi=0.00)$. That is, complete sensitivity to others results in both higher average wealth, and lower ruin rates than the standard model. In the case of one population ( $\delta=0.00$ ), decision makers are generally better off both in terms of wealth and survival as the level of sensitivity to others increases (see Appendix 2, part 1).

\footnotetext{
${ }^{7}$ Thus, each of the four panels shown in Figure 1 compares the standard model to averages of the community model across all levels of the rate of aspiration adjustment for this model $(\alpha=0.10,0.50,1.00)$ and across all levels of the number of possible populations $(M=2,5,10)$.
} 
Figure 1: The relation between the ruin rate of decision makers and the cumulated wealth of the surviving population over $T=10,000$ time periods. Each panel depicts a comparison with the standard model (March 1988) and averages obtained for optimal reference group sensitivity and various levels of switching costs $\left(N=300, W_{i, 0}=3, \delta=0\right)$.

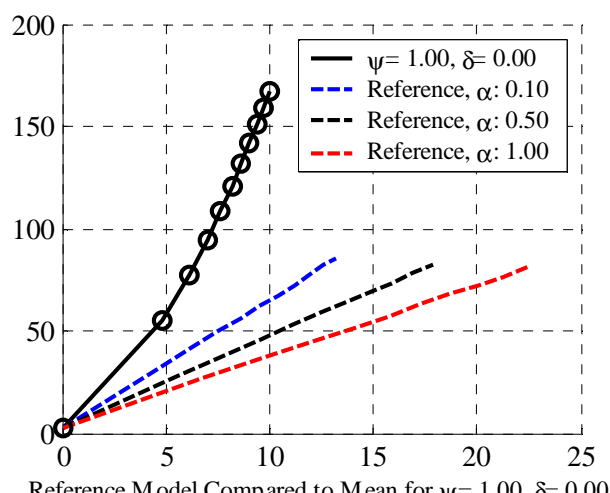

Reference Model Compared to Mean for $\psi=1.00, \delta=0.00$

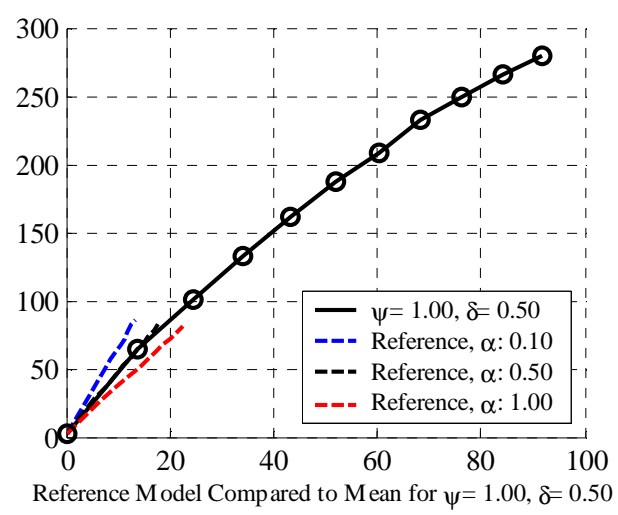

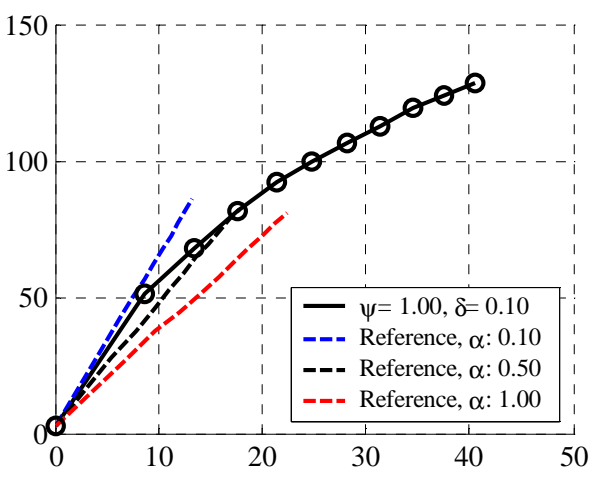

Reference Model Compared to Mean for $\psi=1.00, \delta=0.10$

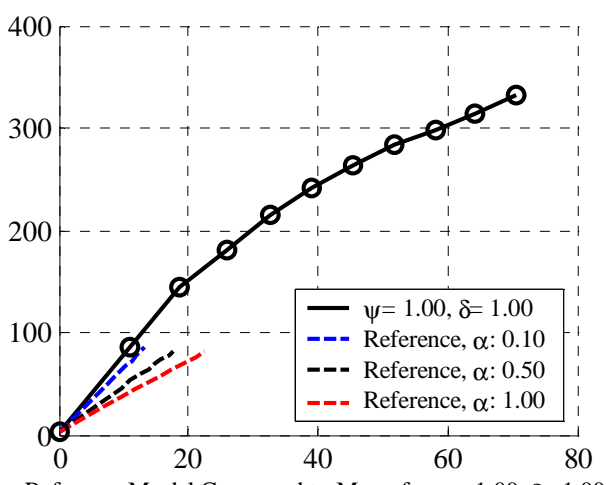

Reference Model Compared to Mean for $\psi=1.00, \delta=1.00$ 


\section{Results for Multiple Populations}

Positive switching costs $(\delta>0)$ lead to segregation among members of multiple populations. Thus, panels two, three and four in Figure 1 show the results for values of $\delta(0.10,0.50,1.00)$ that will give rise to multiple populations. The results for the community model shown in Figure 1 (panels two to four) are averages for $\psi=1.00$, across aspiration levels and across the number of possible populations.

Panels two and three in Figure 1 show the relation between ruin rate and cumulated wealth for complete reference group sensitivity $(\psi=1.00)$ and for both low (panel 2) and moderate (panel 3) switching costs. In both cases, complete sensitivity to the average wealth of the population generally leads to higher average cumulated wealth, and in both cases complete sensitivity to own wealth sometimes leads to lower ruin rates.

The fourth panel in Figure 1 shows the relation between the ruin rate and the cumulated wealth for complete reference group sensitivity $(\psi=1.00)$ and high switching costs $(\delta=1.00)$. In this case, complete sensitivity to the average wealth of the population also dominates the standard model. It is noteworthy that high switching costs lead to higher cumulated wealth than do modest or zero switching costs. How can this be?

In order to answer this question, maximal values of cumulated wealth and minimal ruin rates were identified for each level of the number of possible populations $M$. According to these results, aspirations that adapt completely and instantaneously to the wealth of others $(\psi=1.00, \alpha=1.00)$ dominate aspirations that adapt to own wealth $(\psi<1.00)$ and own prior aspirations $(\alpha<1.00)$. These results holds for any number of possible populations and for any level of switching costs (see Appendices 2 and 3).

The results of the community model lead to insights that complement the main results of the standard model (March 1988). According to the standard model, adaptive levels of aspiration dominate both fixed aspirations and fixed preferences for risk. The results of the standard model were obtained on the basis that decision makers do not consider the wealth of others. In the situation where decision makers can shift among multiple possible populations, complete sensitivity to the average wealth of others dominates sensitivity to own prior aspirations and to own wealth. Does this mean that fixed risk preferences also dominate varying risk preferences?

To determine this, we must consider the basis for updating the decision maker's preference for risk. In the case of complete sensitivity to the wealth of others $(\psi=1.00)$, risk preferences 
effectively vary according to the ratio of the average wealth of others to the wealth of self $\left(R_{i, t}=\Sigma\right.$ $W_{j, t}^{\prime} / W_{i, t}$ when $\psi=1.00$ and $\left.\alpha=1.00\right)$. In order to better understand the results reported above, the following section compares the underlying properties of the standard model and the extensions examined in the present paper.

\section{Comparison of the Reference Group Model and the Standard Model}

The purpose of this comparison for a single population of decision makers is to understand why the reference group model results in both a lower ruin rate and a higher level of wealth accumulation for the population than the standard model. The following section considers the community model.

\section{A Single Reference Group}

Here we compare the underlying properties of the reference group model and the standard model for a single reference group. The standard model can be seen as a special case of the reference group model for a single population that occurs when $\psi=0$ (Equation 3). The reference group model for a single population, in turn, can be seen as a special case of the community model of multiple reference groups that occurs when the switching costs, $\delta$, are zero (Equation 5). When $\delta=$ 0 , decision makers can move freely (Equation 5), and all decision makers will be gathered in one population after the first time-step. ${ }^{8}$

The general properties of the standard model can be described as follows (March 1988). In the standard model, some decision makers will accumulate losses while others will accumulate gains. If the accumulated losses are equal to, or larger than, the initial stake, the decision maker is ruined and is therefore replaced by a new decision maker. According to Equations (1) and (2), as $\alpha$ approaches zero, $A_{i, t}$ approaches a fixed value, and the wealthy decision makers will reduce their risk taking (i.e., $R_{i, t}$ approaches zero as a decision maker continues to accumulate wealth in excess of the initial stake). Consequently, fluctuations in wealth will decrease as decision makers accumulate more wealth. Gradually, those decision makers with wealth in excess of the initial stake will inhabit the population, and the probability of their replacement will tend to zero.

\footnotetext{
${ }^{8}$ In subsequent time steps, newborn decision makers are assigned to one out of the $M$ populations with probability $1 / M$, exactly as in the initial allocation. When $\delta=0$, a newborn decision maker will move to the remaining population in the second time step of its life.
} 
It is useful to think of a decision maker's wealth distribution over the course of play as a matrix of transition probabilities, each defined as the probability that a decision maker's level of cumulated wealth at a particular time-step can be reached from any level of cumulated wealth at a different time-step. Let us refer to this as a decision maker's wealth distribution matrix. The decision maker's wealth distribution matrix has one absorbing state (cumulated wealth zero) and a number of interior states (cumulated wealth above zero). Initially, every interior state of cumulated wealth is transient. As the exogenously given rate of aspiration adjustment, $\alpha$, approaches zero, the aspiration level approaches a fixed value (Equation 2), and as more decision makers with wealth in excess of the initial stake gradually inhabit the population, their level of preferred risk, $R_{i, t}$, will approach zero (Equation 1). Therefore, in later stages of the game, the interior states of their wealth distribution matrix will recurrently visit a shrinking neighbourhood of cumulated wealth. This happens because the pay-off is determined by a draw from a normal distribution with expectation 0 and standard deviation $R_{i, t}$, the preference for risk. ${ }^{9}$ By contrast, as $\alpha$ approaches $1, A_{i, t}$ approaches $W_{i, t}$, and the level of preferred risk, $R_{i, t}$, will approach the fixed value of 1 (Equation 1). In this case, the interior states of any decision maker's wealth distribution matrix remain transient. Clearly, the minimal ruin rate occurs as $\alpha$ approaches zero, and the maximal ruin rate occurs when $\alpha$ approaches 1 (since the basin of attraction of the absorbing state is larger in the latter case).

What of the population's maximal accumulation of wealth? In the standard model the cumulative value of the population's wealth is positive and increasing with the number of time steps. The reason for this is that a decision maker's choice of risk is not limited by her cumulated wealth. ${ }^{10}$ This introduces an asymmetry. Typically, a decision maker who is close to ruin will prefer a level of risk that creates uncovered losses in excess of the initial stake, $W_{i, 0}$, should the outcome be unfavourable. In this case, nature must cover the losses. By contrast, if the outcome is favourable, the decision maker will appropriate the gains. When the rate of aspiration adjustment, $\alpha$, approaches zero, the aspiration level, $A_{i, t}$, approaches a fixed value (Equation 2). As the aspiration level approaches a fixed value, the level of preferred risk, $R_{i, t}$, will increase for a decision maker who is close to ruin. Therefore, the maximal accumulation of wealth for the population will occur for a low value of $\alpha$. However, as $\alpha$ approaches zero, the ruin rate will also decrease. A very small ruin rate will reduce the number of replacements, the number of uncovered losses and thereby the

\footnotetext{
${ }^{9}$ Since the normal distribution function is continuous, this implies that a decision maker's wealth distribution has a fixed point.

${ }^{10}$ Our assumption is consistent with self employment under a rather 'forgiving' bankruptcy system such as the US

(Armour and Cumming 2005, Dosi 1990). In contrast, stricter bankruptcy laws (as in many European countries) tend to diminish entrepreneurship and risk taking.
} 
wealth accumulated by the population. Therefore, we expect the maximal accumulation of wealth for the population to occur for a low value of $\alpha>0$. By contrast, as $\alpha$ approaches 1 , the level of preferred risk, $R_{i, t}$, will also approach the fixed value of 1 . In this case the amount of each uncovered loss will be limited. From this it follows that the population's maximal accumulation of wealth in the standard model will occur for $0<\alpha<1$ and, as mentioned above, the minimal ruin rate occurs as $\alpha$ approaches zero.

Why does increased reference group sensitivity result in both a lower ruin rate and a higher level of accumulation of wealth for the population (see panel one of Figure 1)? Here, again, it is useful to think of a decision maker's wealth distribution over the course of play as a matrix of transition probabilities. As mentioned above, every interior state of accumulated wealth is initially transient. In the standard model the interior states will recurrently visit a shrinking neighbourhood of accumulated wealth as the exogenously given rate of aspiration adjustment, $\alpha$, approaches zero. This eventually happens for every decision maker.

Now, consider the limit case of complete reference group sensitivity ( $\psi=1$ in Equation 3) and an instantaneously adapting rate of aspiration adjustment $(\alpha=1)$. A decision maker's level of preferred risk is then defined as the ratio of average accumulated wealth of the population to a decision maker's own wealth $\left(W_{j, t}^{\prime} / W_{i, t}\right)$. As a decision maker's level of cumulated wealth exceeds the average accumulated wealth of the population, the level of preferred risk will decrease and the interior states of the wealth matrix will recurrently visit a shrinking neighbourhood of cumulated wealth. The more excessive the decision maker's wealth over the population average, the smaller the neighbourhood of interior states that are recurrently visited. On the other hand, as a decision maker's level of cumulated wealth falls below the average accumulated wealth of the population, the level of preferred risk increases and the interior states of the wealth distribution matrix remain transient. For a given level of a population's accumulated wealth, the distribution of risk preferences is symmetric around the mean. Because of this symmetry there will continue to be a fraction of decision makers who at times experience ruin and at times enjoy very large gains. In consequence, the average accumulated population wealth will increase. Half the population will remain risk prone, and a small share of the population will always prefer large levels of risk.

Thus, we should expect that in the case of complete reference group sensitivity, the ruin rates will be about half of the ruin rates we observed in the standard model. As depicted in panel one of Figure 1, this is indeed the case. In the case of complete reference group sensitivity, a small and unfortunate fraction of the population will experience levels of wealth below the population 
average, $W_{i, t} \ll W_{j, t}^{\prime}$, and will therefore continue to prefer large levels of risk. For any $\alpha$ the aspiration level, $A_{i, t+1}$, is a linear combination of $W_{j, t}^{\prime}, W_{i, t}$ and $A_{i, t}$ (Equation 3). In the case of $W_{i, t}$ $\ll W_{j, t}{ }^{\prime}$, the prior aspiration $A_{i, t}$ is also below average wealth $W_{j, t}{ }_{j, t}$ The consequence is that some decision makers with complete reference group sensitivity will prefer much higher levels of risk than decision makers in the standard model. Since the uncovered losses of decision makers who prefer higher risk will also be higher, it follows that the population's accumulated wealth will be higher for the model of complete reference group sensitivity than for the standard model. As panel one in Figure 1 shows, the model of complete reference group sensitivity dominates the standard model for any time-step with respect to both lower ruin rates and higher levels of accumulated population wealth.

It is also interesting to consider the model of complete reference group sensitivity for each alternative level of $\alpha$. In this model, the aspiration level, $A_{i, t+1}$, reaches a maximal value as the weight of prior aspiration, $A_{i, t}$, approaches zero. This occurs as the rate of aspiration adjustment, $\alpha$, approaches 1 (Equation 3). As $\alpha$ approaches 1, some decision makers with complete reference group sensitivity will prefer maximal levels of risk. Therefore, the maximal accumulation of wealth for the population of complete reference group sensitivity will occur for a high value of $\alpha$. However, as $\alpha$ approaches 1 , the ruin rate will also decrease. Since this will reduce the number of replacements and thereby the wealth accumulated by the population, we would expect the maximal accumulation of wealth for the population to occur for a high value of $\alpha<1$, and this is indeed the case. $^{11}$

\section{Multiple Reference Groups}

As mentioned above, the context of a single reference group can be seen as a special case of the community model with multiple reference groups. When switching costs, $\delta$, are zero, segregation among multiple reference groups disappears and a single reference group remains. We next consider the community model of multiple reference groups. This is the case of positive switching costs, $0<\delta$. In the current specification of the community model, alternative numbers of possible populations were examined $(M=2,5,10)$. With probability $1 / M$, a decision maker is initially assigned to one out of the $M$ populations. The decision maker moves if the average cumulated wealth in any other population, $W_{-j, t}^{\prime}$, is higher than the average accumulated wealth of the decision maker's own population, $W_{j, t}$, net of switching costs, $\delta$. Otherwise, the decision maker stays. The

\footnotetext{
${ }^{11}$ The decomposition of the results is not shown here, but is obtainable from the author upon request.
} 
number $M$ is the maximal number of possible populations. The actual number of populations that emerge is determined by the dynamics of the process over the course of play. In the following, the results obtained for each level of $M(=2,5,10)$ are briefly considered. ${ }^{12}$

Two possible populations $(M=2)$. A summary of the results obtained for $M=2$ are shown in Figure 4 of Appendix 3. When the costs of switching, $\delta$, are positive, two populations will persist. One small population will contain the unfortunate decision makers with low accumulated wealth; a larger population includes the lucky decision makers with high levels of accumulated wealth. For low levels of switching costs, $\delta$, most decision makers will gather in the population that emerges as the most wealthy. As the switching $\operatorname{costs}, \delta$, increase, the decision makers become more evenly distributed across the two populations. ${ }^{13}$

As can be seen from panel three of Figure 4, both survival and the population's accumulated wealth are jointly maximized for zero switching costs $(\delta=0)$ or for high switching costs $(\delta=1)$. That is, in the community model of multiple populations, higher switching costs dominate lower switching costs (averages across other effects). Why is this? First, the progress of each population follows the dynamics for a single population, as described above. Since we now know that a positive level of reference group sensitivity $(\psi>0)$ will lead to both lower ruin rates and higher accumulated population wealth, we limit our focus to this possibility. Second, a decision maker in the poorer population may experience a lucky draw, motivating a move to the richer population. In the time step immediately following her move, this decision maker will use the new and higher average of accumulated population wealth to determine the preferred risk (since $\psi>0$ ). As a result the new entrant to the richer population will usually be more risk prone than the incumbents. Because of this entry effect, some decision makers will enjoy very large gains, but the size of uncovered losses from the unsuccessful entrants will also grow. As $\delta$ increases, an entrant will have little wealth relative to the incumbent population and will therefore prefer a more risky choice than in the situation of a lower $\delta$. This, then, gives rise to the counterintuitive result that higher switching costs dominate lower switching costs.

Finally, it is worth noting that complete reference group sensitivity $(\psi=1)$ dominates any other level of reference group sensitivity (panel two in Figure 4). As was the case with a single

\footnotetext{
${ }^{12}$ The detail of the multiple populations results is not shown here, but can be obtained from the author upon request.

${ }^{13}$ In the actual case for $\delta=0.10$ about $2 / 3$ of the decision makers, on average, will be located in the more wealthy population. For $\delta=0.50$ or 1.00 the fraction of the decision makers who, on average, are located in the more wealthy population is a little higher than $1 / 2$.
} 
population, a rate of aspiration adjustment between zero and $1(0<\alpha<1)$, on average, dominates other levels of $\alpha$. If we examine all combinations of the parameter values, however, it turns out that both minimal ruin rates and maximal accumulation of population wealth occur when the aspiration levels adapt instantaneously to the average wealth of the population $(\alpha=1)$ and the reference group sensitivity is complete $(\psi=1)$. The maximal values are shown in panel four of Figure 4.

Five or ten possible populations $(M=5,10)$. As the number of possible populations increases, one rich population and a number of poor populations emerge. Within this ensemble of poor populations, the slightly richer populations will have more members than the poorer populations. In the case of ten possible populations, each of the poor populations has few members and the accumulated population wealth is very low. The poor populations become incubators for the rich population. When some member of a poor population experiences the lucky draw resulting in a move to the rich population, this lucky decision maker will, as an entrant, usually prefer a very high level of risk. The occasional entrant to the rich population will therefore either leave with a very high loss that remains uncovered or quickly increase her wealth to the current average level of the rich population.

When the entrant is ruined, a newborn decision maker is placed in one of the $M$ populations with probability $1 / M$. In the case of ten populations, the newborn decision maker is placed in the rich population with probability $1 / 10$ and in a poor population with probability $9 / 10$. As the number of populations increases, most newborn decision makers, therefore, will enter the rich population through the poor. This explains why the maximal accumulated population wealth (which occurs for $\psi=1$ and $\alpha=1$ ) increases as the number of populations increases (Appendix 2 and 3).

In the case of five or ten populations, complete reference group sensitivity $(\psi=1)$ dominates any other level of reference group sensitivity (panel two in Figures 5 and 6). It is further the case that an instantaneous rate of aspiration adjustment $(\alpha=1)$ also on average leads to both lower ruin rates and higher accumulated population wealth (panel one in Figures 5 and 6).

As depicted in panel three of Figures 5 and 6, both survival and the accumulated wealth of the population, reach maximal values for either zero switching costs $(\delta=0)$ or for high switching costs $(\delta=1)$. A closer examination of the alternative combinations of parameter values shows that both minimal ruin rates and maximal accumulation of population wealth occur when the aspirations adapt instantaneously to the average wealth of the population $(\alpha=1)$ and to complete reference group sensitivity $(\psi=1)$. These maximal values are shown in panel four of Figures 5 and 6 . Note here the dramatic increase in the accumulated wealth of the population when panel four in Figure 6 
is compared with the results of the standard model. Over 10,000 time steps the maximal values of accumulated wealth for the community model are more than 10 times the wealth of the population of the standard model for the same ruin rate.

\section{Discussion}

The community model has not previously been discussed in the literature, and only a few studies have considered aspirations that track the average wealth of a reference group. Posch et al. (1999) and Weibull (2002) are relatively recent examples. Weibull demonstrates how to construct a model of adapting rules that lead to the replicator dynamics and considers the possibility that an aspiration level tracks the average wealth of others. This appears to be a very promising extension of previous studies of social learning and conformist behaviour. Unfortunately the analytical approach in Weibull is not directly comparable to the model in the present study.

In another study, Posch et al. use the standard function of convex updating, which is used in the present study (Equation 2) to derive analytical results in games, not against nature, but against other players. Where the present study uses a simulation approach to study stochastic updating of aspirations, Posch et al.'s study is limited to deterministic updating. Their primary result is that natural selection, in the realm of social interactions, stimulates the emergence of faculties that enable consideration of more than just registering one's own payoff sequence. For example, Posch et al. consider a strategy where players use as the aspiration level in round $n$ the maximum of their own and their co-player's payoff in round $n-1$. This strategy, an instance of the principle of "keeping up with the Joneses", is similar to the definition of complete reference sensitivity employed in the present study. As regards the effect of complete reference sensitivity, Posch et al. conclude that envy is often an efficient impulse. This result hints at "the royal Swedish envy" (Daun 1989) and its dark expression in the Scandinavian "Law of Jante" as important cultural traits that stimulate the efficiency observed in these cultures.

Posch et al. argue that it requires a substantial cognitive ability to monitor other players' payoffs and a high level of empathy to compare them with one's own payoff. They find that this observation is consistent with the "currently favoured opinion that the major selective stimulus for the evolution of intelligence comes, not from games against nature (like optimal foraging or antipredator behaviour), but from the demands of social interactions" (p. 1434). In view of the results from the present study, the currently favoured opinion may need revision. Also in the present study, which is a game against nature, does "keeping up with the Joneses" turn out to be the most 
efficient strategy? Clearly, our results show that a game against nature provides a selective stimulus for the evolution of human intelligence similar to what was identified by Posch et al.

The results from the present study have a number of implications for real-world contexts. The community effect applies to social organizations where significant switching costs sustain segregation among a number of individual populations. Obvious examples include demographic distributions, research communities, sports teams, and work groups in firms. Newcomers to a higher social stratum may tend to accept the performance of their new reference group as an achievement target. In such cases, the community effect provides a stylized description of the dynamics, particularly if the newcomer tends to focus on the mean performance of its new reference group. An obvious example is the instance of "royal Swedish Envy" where aspirations are driven by sensitivity to the mean of a reference group. Since Scandinavian consequences of failure in the job market are rather "forgiving", risk taking associated with bold career moves will be further stimulated.

Also in research communities, the community model offers an illuminating description of the dynamics associated with entry at higher levels of the professional ladder. New $\mathrm{PhD}$ students, assistant professors, and so on may accept the mean performance of their more seasoned peers as a level of aspiration. To the extent that they focus on an upward moving target, they will tend to be rather risk prone. The effect will be a dynamics where new entrants most often will fail, but on rare occasions will realize spectacular careers. It is a process where newcomers tend to be useful waste in an evolutionary process that stimulates continuous increases in performance.

Quite similar dynamics are conceivable in movements among members of sports teams, workgroups in firms, and so on. This model also seems to capture dynamics among firms that shift strategic groups and industries (we would expect "forgiving" US bankruptcy laws to stimulate this dynamics whereas European bankruptcy laws would tend to dampen risk taking). It may even be a fair description of Nation States that move upwards in the hierarchy of international alliances, for example, as most newcomers to the EEC have done. Detailed consideration of this topic in future research, empirical as well as theoretical, would appear to be exciting and to promise further advances in the behavioural research programme inspired by March and Simon (1958) and Cyert and March (1963). One of the first items on such an agenda must be an examination of the critical assumptions of the community model. In particular, we need to get more systematic knowledge about the weight decision makers put on the performance of others and whether decision makers focus on the mean performance of their reference group or use other referent targets. 


\section{Conclusion}

The model developed in the present study continues the trend towards greater emphasis on social interaction, relative comparisons, and the context of decision-making rather than seeing the individual as facing a fixed decision environment with absolute decision criteria. The main result of our model is that reference group comparisons generally provide a more important basis for variable risk strategies than the decision maker's own situation. As multiple populations were considered, the reference group context became a dominating driver of performance. Both minimal ruin rates and maximal accumulation of population wealth occurred when the aspirations adapted instantaneously to the average wealth of the population and the reference group sensitivity was complete. This result dramatically illustrates the importance of the social context in decisionmaking. It implies significant gains in developing a richer understanding of how the social context impinges on individual choice in decision making. 


\section{References}

Armour, J., Cumming, D.J., 2005. Bankruptcy Law and Entrepreneurship. American Law \& Economics Association Annual Meetings, Paper 26.

Augier, M., 2001. Simon says: Bounded rationality matters. Journal of Management Inquiry 10, 268-275.

Augier, M., Kreiner, K., 2000. An interview with James G. March. Journal of Management Inquiry 9, 284-297.

Benaim, M., Weibull, J. W., 2001. Deterministic approximation of stochastic evolution in games, Mimeo, Department of Economics, Stockholm School of Economics, Stockholm, Sweden.

Berg, C. C., 1974. Individual decisions concerning the allocation of resources for projects with uncertain consequences. Management Science 21, 98-105.

Borgers, T. \& Sarin, R. 2000, "Naive Reinforcement Learning with Endogenous Aspirations", International Economic Review, vol. 41, no. 4, pp. 921-950.

Binmore, K. \& Samuelson, L. 1997, "Muddling Through: Noisy Equilibrium Selection", Journal of Economic Theory, vol. 74, pp. 235-265.

Björnerstedt, J. \& Weibull, J. W. 1996, "Nash Equilibrium and Evolution by Imitation," in The Rational Foundations of Economic Behaviour, K. J. e. al. Arrow, ed., MacMillan, London, pp. 155171.

Clawson, J. 1950, "Lewin's Vector Psychology and the Analysis of Motives in Marketing," in Theory in Marketing. Selected Essays, R. Cox \& W. Alderson, eds., Richard D. Irwin, Inc., Chicago, pp. 41-64.

Cyert, R. M., Dill, W. R., \& March, J. G. 1958, "The Role of Expectations in Business Decision Making", Administrative Science Quarterly, Special Issue on Decision Making, vol. 3, no. 3, Special Issue on Decision Making, pp. 307-340.

Cyert, R. M. \& March, J. G. 1963, A Behavioral Theory of the Firm Blackwell Publishers, Cambridge, MA.

Daun, Å. 1989. Svensk mentalitet [Swedish mentality]. Simrishamn, Sweden: Rabén\&Sjögren.

Dosi, G. 1990. "Finance, Innovation and Industrial Change", Journal of Economic Behavior \& organization, vol 13, pp. 299-319.

Festinger, L. 1954, “A Theory of Social Comparison Processes”, Human Relations, vol. 7, pp. 117140.

Frey, B. \& Stutzer, A. 2002, “What Can Economists Learn from Happiness Research?”, Journal of Economic Literature, vol. 40, no. 2, pp. 402-435. 
Gale, J., Binmore, K., \& Samuelson, L. 1995, "Learning to be Imperfect: The Ultimatum Game", Games and Economic Behavior, vol. 8, pp. 56-90.

Greve, H. R. 1998, "Performance, Aspirations, and Risky Organizational Change", Administrative Science Quarterly, vol. 43, no. 1, pp. 58-86.

Herriott, S., Levinthal, D. A., \& March, J. G. 1985, "Learning From Experience in Organizations", American Economic Review, vol. 75, no. 2, pp. 298-302.

Kagel, J. H. \& Roth, A. E. 1995, The Handbook of Experimental Economics, Princeton University Press, Princeton.

Kahneman, D. \& Tversky, A. 1979, "Prospect Theory: An Analysis of Decision under Risk", Econometrica: Journal of the Econometric Society, vol. 47, no. 2, pp. 263-292.

Lant, T. K. 1992, "Aspiration Level Adaptation: An Empirical Exploration", Management Science, vol. 38, no. 5, pp. 623-644.

Levinthal, D. A. \& March, J. G. 1981, "A Model of Adaptive Organizational Search", Journal of Economic Behavior \& Organization, vol. 2, pp. 307-333.

Lewin, K. 1939, "Field Theory and Experiment in Social Psychology: Concepts and Methods", American Journal of Sociology, vol. 44, no. 6, pp. 868-896.

Lewin, K. \& Others 1944, "The Level of Aspiration," in Personality and the Behavior of Disorders, J. M. Hunt, ed., Ronald Press, New York.

Luce, R. D. \& von Winterfeldt, D. 1994, "What Common Ground Exists for Descriptive, Prescriptive, and Normative Utility Theories?", Management Science, vol. 40, no. 2, pp. 263-279.

March, J. G. 1996, "Learning to Be Risk Averse", Psychological Review, vol. 103, pp. 309-319.

March, J. G. \& Shapira, Z. 1987, "Managerial Perspectives on Risk and Risk Taking", Management Science, vol. 33, no. 11, pp. 1404-1418.

March, J. G. \& Simon, H. A. 1958, Organizations John Wiley, New York.

March, J. G. 1988, "Variable Risk Preferences and Adaptive Aspirations", Journal of Economic Behavior \& Organization, vol. 9, pp. 5-24.

March, J. G. \& Shapira, Z. 1992, "Variable Risk Preferences and the focus of Attention", Psychological Review, vol. 99, pp. 172-183.

Payne, J. W., Laughhunn, D. J., \& Crum, R. 1981, "Further Tests of Aspiration Level Effects in Risky Choice Behavior", Management Science, vol. 27, no. 8, pp. 953-958.

Payne, J. W., Laughhunn, D. J., \& Crum, R. 1984, "Multiattribute Risky Choice Behavior: The Editing of Complex Prospects", Management Science, A Special Issue on Multiple Criteria, vol. 30, no. 11, A Special Issue on Multiple Criteria, pp. 1350-1361. 
Payne, J. W., Laughhunn, D. J., \& Crum, R. 1980, "Translation of Gambles and Aspiration Level Effects in Risky Choice Behavior", Management Science, vol. 26, no. 10, pp. 1039-1060.

Posch, M. 1999, Win - Stay, Lose - Shift Strategies for Repeated Games - Memory Length, Aspiration Levels, And Noise. Journal of Theoretical Biology, vol. 198, 183-195.

Posch, M., Pichler, A., \& Sigmund, K. 1999, "The Efficiency of Adapting Aspiration Levels", Proc. R. Soc. Lond. B, vol. 266, 1427-1435.

Schlag, K. H. 1998, "Why Imitate, and If So, How?", Journal of Economic Theory, vol. 78, pp. 130156.

Schumpeter, Joseph A. 1934, The Theory of Economic Development, Harvard University Press.

Simon, H. A. 1956, "Rational Choice and the Structure of the Environment", Psychological Review, vol. 63, no. March, pp. 129-138.

Thibaut, J.W., \& Kelley, H. H. 1959, The Social Psychology of Groups, New York: Wiley.

Weibull, J. W. 2002, Testing game theory, Mimeo, Department of Economics, Stockholm School of Economics, Sweden, Stockholm, SSE WP 382.

West, P. M. \& Broniarczyk, S. M. 1998, "Integrating Multiple Opinions: The Role of Aspiration Level on Consumer Response to Critic Consensus", Journal of Consumer Research, vol. 25, no. 1, pp. 38-51. 


\section{Appendix 1}

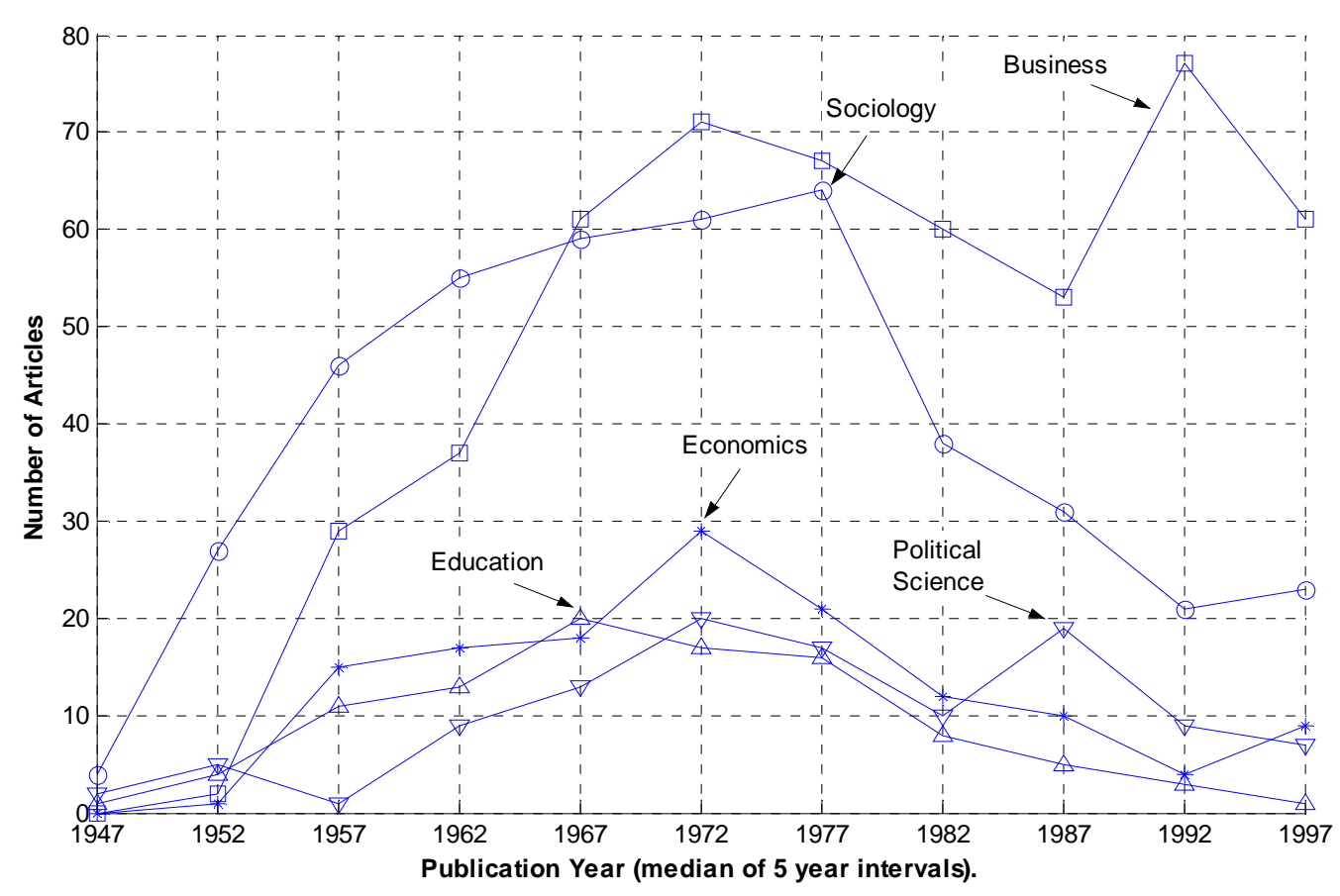

Figure 2: Absolute number of articles on aspiration levels published in each five-year period between 1945 and 1999. Results of a comprehensive search of the J-STOR database conducted 3/3/2003. The search terms used were "ASPIRATION LEVEL", "ASPIRATION LEVELS", and "LEVEL OF ASPIRATION". The search included all journals for each of the categories shown: (1) economics, 26 journals in 1999, (2) education, 6 journals in 1999, (3) political science, 26 journals in 1999, (4) sociology, 29 journals in 1999, and (5) business, 46 journals in 1999. In the J-STOR database, the category "business" includes some journals that are also included in "economics" and "sociology". In order that the reader may easily verify the results, the content of all categories, including "business", were left as defined in the J-STOR database. The numbers are summaries of five-year periods. Each five-year period is represented by its median. 


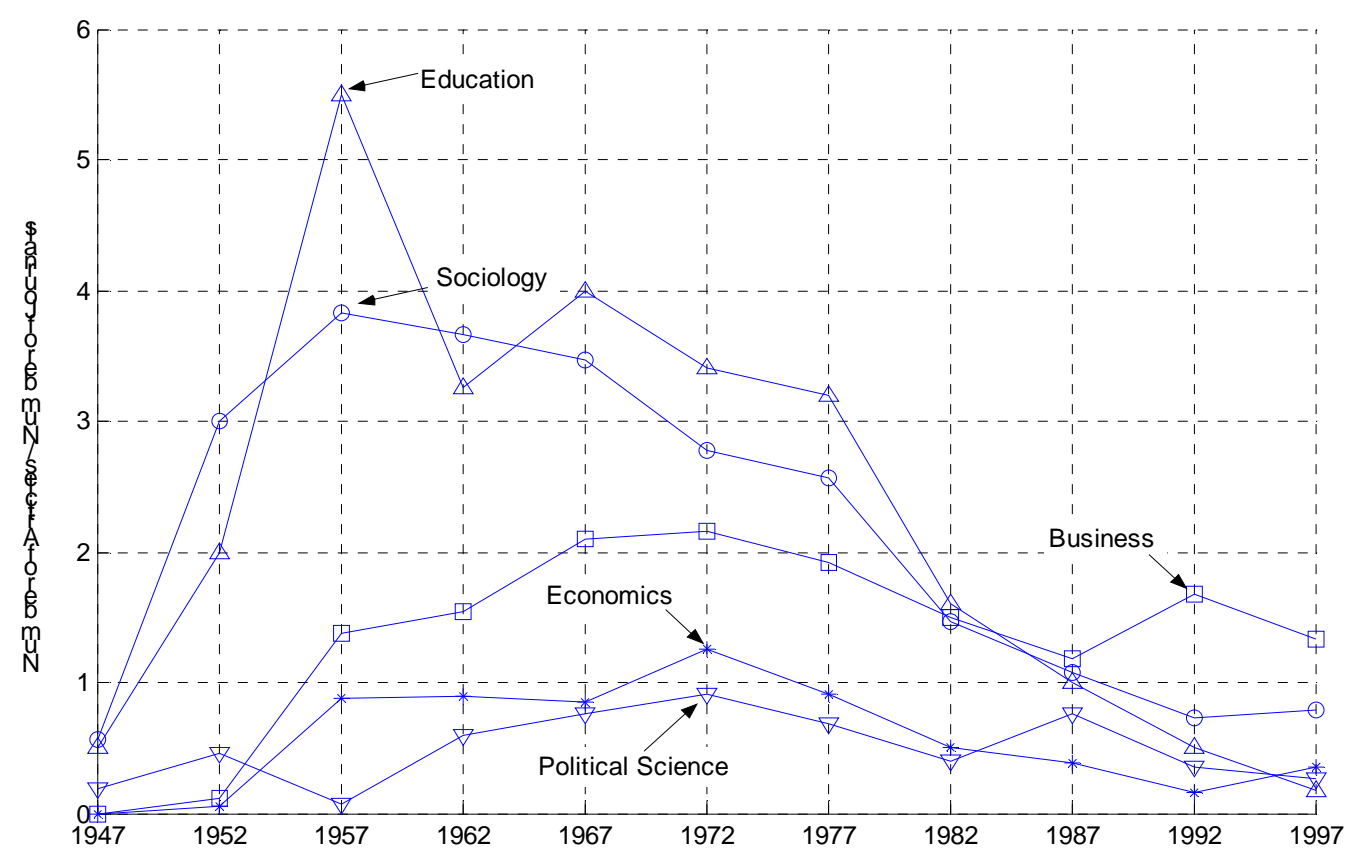

Figure 2: The ration of number of articles in each five-year period to number of journals that five year period. Results of a comprehensive search of the J-STOR database conducted 3/3/2003. 


\section{Appendix 2}

Table 1, Part 1

\begin{tabular}{|c|c|c|c|c|c|c|c|}
\hline \multirow[b]{2}{*}{$\delta$} & \multirow[b]{2}{*}{$\psi$} & \multirow[b]{2}{*}{$\alpha$} & \multirow[b]{2}{*}{$\operatorname{Max}$} & \multicolumn{3}{|c|}{ Number of Populations } & \multirow{2}{*}{$\begin{array}{c}\text { Row } \\
\text { Means }\end{array}$} \\
\hline & & & & 2 & 5 & 10 & \\
\hline \multirow{12}{*}{0.00} & 0.00 & 0.10 & & 6.50 & 6.50 & 6.50 & 6.9 \\
\hline & & 0.50 & & 4.63 & 4.63 & 4.63 & 4.6 \\
\hline & & 1.00 & & 3.61 & 3.61 & 3.61 & 3.6 \\
\hline & 0.10 & 0.10 & & 8.16 & 8.17 & 8.15 & \\
\hline & & 0.50 & & 7.04 & 6.93 & 7.06 & 7.0 \\
\hline & & 1.00 & & 6.20 & 6.33 & 6.42 & 6.3 \\
\hline & 0.50 & 0.10 & & 11.58 & 11.42 & 11.59 & 11.5 \\
\hline & & 0.50 & & 11.84 & 12.05 & 12.27 & $12 .($ \\
\hline & & 1.00 & & 12.53 & 13.11 & 13.39 & 13.0 \\
\hline & 1.00 & 0.10 & & 14.27 & 14.52 & 14.60 & 14. \\
\hline & & 0.50 & & 17.18 & 18.18 & 18.52 & 17.9 \\
\hline & & $1.00=$ & & 19.41 & 21.14 & 22.40 & 20. \\
\hline \multirow{12}{*}{0.10} & 0.00 & 0.10 & & 3.10 & 0.08 & 0.08 & $1 .($ \\
\hline & & 0.50 & & 2.77 & 0.04 & 0.04 & 0.9 \\
\hline & & 1.00 & & 2.30 & 0.02 & 0.02 & 0.7 \\
\hline & 0.10 & 0.10 & & 2.99 & 0.09 & 0.09 & $1 .($ \\
\hline & & 0.50 & & 2.46 & 0.05 & 0.05 & 0.8 \\
\hline & & 1.00 & & 2.26 & 0.03 & 0.03 & 0.7 \\
\hline & 0.50 & 0.10 & & 3.44 & 0.30 & 0.31 & 1.3 \\
\hline & & 0.50 & & 4.26 & 0.43 & 0.40 & 1.7 \\
\hline & & 1.00 & & 4.06 & 0.38 & 0.38 & 1.6 \\
\hline & 1.00 & 0.10 & & 4.25 & 1.71 & 1.67 & 2.5 \\
\hline & & 0.50 & & 4.16 & 3.27 & 3.37 & 3.6 \\
\hline & & $1.00=$ & & 4.53 & 4.68 & 4.96 & 4.7 \\
\hline
\end{tabular}

*Cumulative Wealth/ Cumulative Ruin at Time T=10000. 
Table 1, Part 2

\begin{tabular}{|c|c|c|c|c|c|c|c|}
\hline \multirow[b]{2}{*}{$\delta$} & \multirow[b]{2}{*}{$\psi$} & \multirow[b]{2}{*}{$\alpha$} & \multirow[b]{2}{*}{$\operatorname{Max}$} & \multicolumn{3}{|c|}{ Number of Populations } & \multirow{2}{*}{$\begin{array}{c}\text { Row } \\
\text { Means }\end{array}$} \\
\hline & & & & 2 & 5 & 10 & \\
\hline \multirow{12}{*}{0.50} & 0.00 & 0.10 & & 6.52 & 0.89 & 0.01 & 2.47 \\
\hline & & 0.50 & & 4.63 & 0.88 & 0.01 & 1.84 \\
\hline & & 1.00 & & 3.71 & 0.78 & 0.01 & 1.50 \\
\hline & 0.10 & 0.10 & & 8.01 & 0.76 & 0.01 & 2.93 \\
\hline & & 0.50 & & 7.17 & 0.65 & 0.01 & 2.61 \\
\hline & & 1.00 & & 6.51 & 0.74 & 0.01 & 2.42 \\
\hline & 0.50 & 0.10 & & 11.38 & 0.74 & 0.02 & 4.04 \\
\hline & & 0.50 & & 12.86 & 0.54 & 0.02 & 4.47 \\
\hline & & 1.00 & & 12.61 & 0.50 & 0.02 & 4.38 \\
\hline & 1.00 & 0.10 & & 14.56 & 0.45 & 0.19 & 5.07 \\
\hline & & 0.50 & & 18.45 & 1.95 & 2.01 & 7.47 \\
\hline & & 1.00 & & 20.58 & 10.41 & 18.43 & 16.47 \\
\hline \multirow{12}{*}{1.00} & 0.00 & 0.10 & & 6.44 & 5.99 & 0.15 & 4.19 \\
\hline & & 0.50 & & 4.58 & 3.82 & 0.17 & 2.86 \\
\hline & & 1.00 & & 3.64 & 3.17 & 0.15 & 2.32 \\
\hline & 0.10 & 0.10 & & 8.13 & 5.24 & 0.14 & 4.50 \\
\hline & & 0.50 & & 7.23 & 5.35 & 0.10 & 4.23 \\
\hline & & 1.00 & & 6.41 & 4.68 & 0.14 & 3.74 \\
\hline & 0.50 & 0.10 & & 11.94 & 4.65 & 0.11 & 5.57 \\
\hline & & 0.50 & & 12.42 & 4.32 & 0.07 & 5.61 \\
\hline & & 1.00 & & 12.55 & 6.43 & 0.08 & 6.35 \\
\hline & 1.00 & 0.10 & & 15.09 & 3.68 & 0.08 & 6.28 \\
\hline & & 0.50 & & 18.24 & 3.14 & 2.51 & 7.96 \\
\hline & & 1.00 & & 20.24 & 11.10 & 46.47 & 25.94 \\
\hline \multicolumn{4}{|c|}{ Column Means } & 8.70 & 4.55 & 4.41 & 5.88 \\
\hline
\end{tabular}

*Cumulative Wealth/ Cumulative Ruin at Time $\mathrm{T}=10000$ 


\section{Appendix 3}

Figure 4: Two Populations

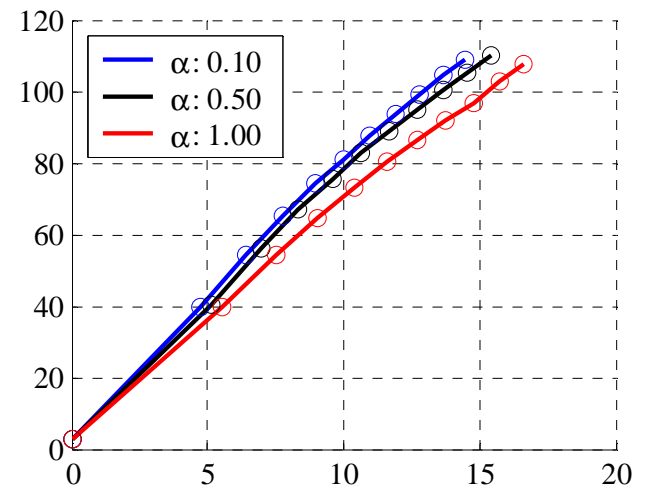

Ratio of Number Ruined to Size of Population 2 Markets

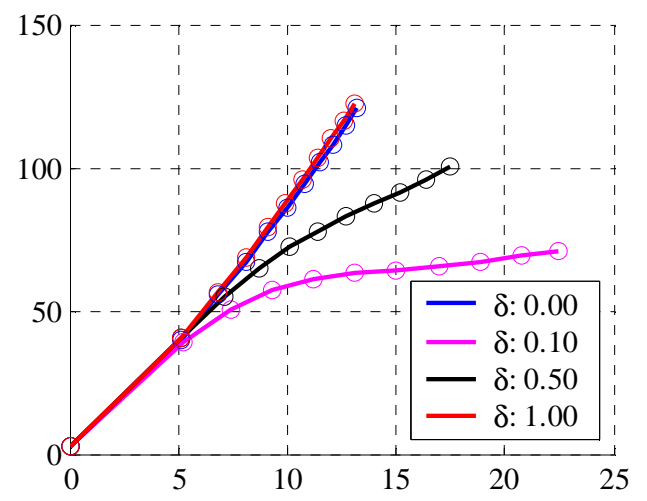

Ratio of Number Ruined to Size of Population 2 Markets
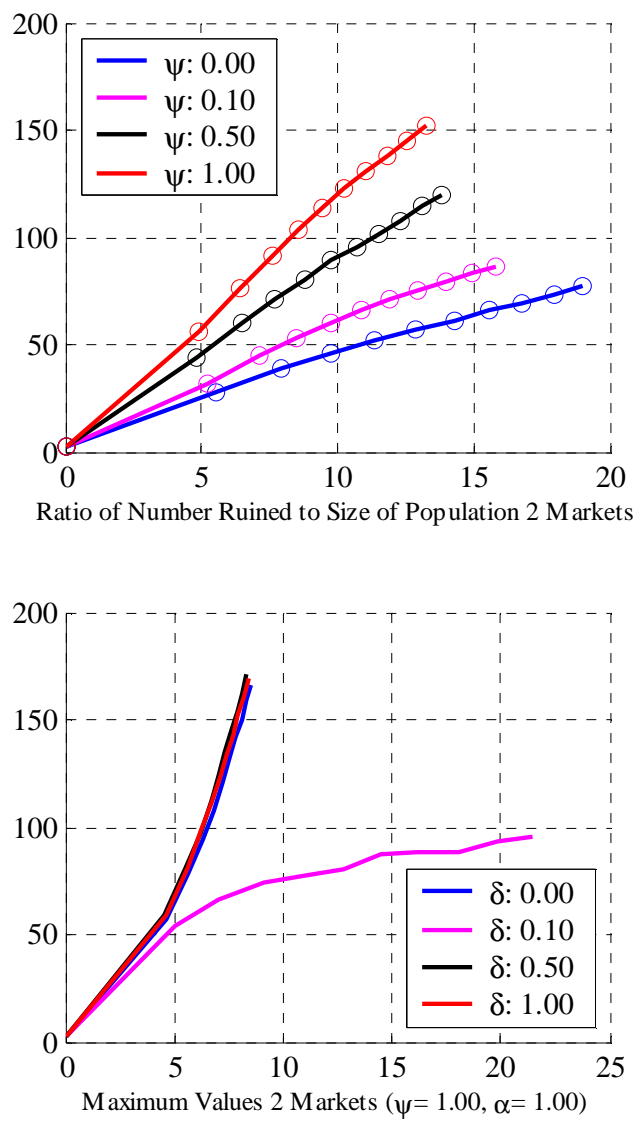


\section{Appendix 3, ctd.}

Figure 5: Five Populations
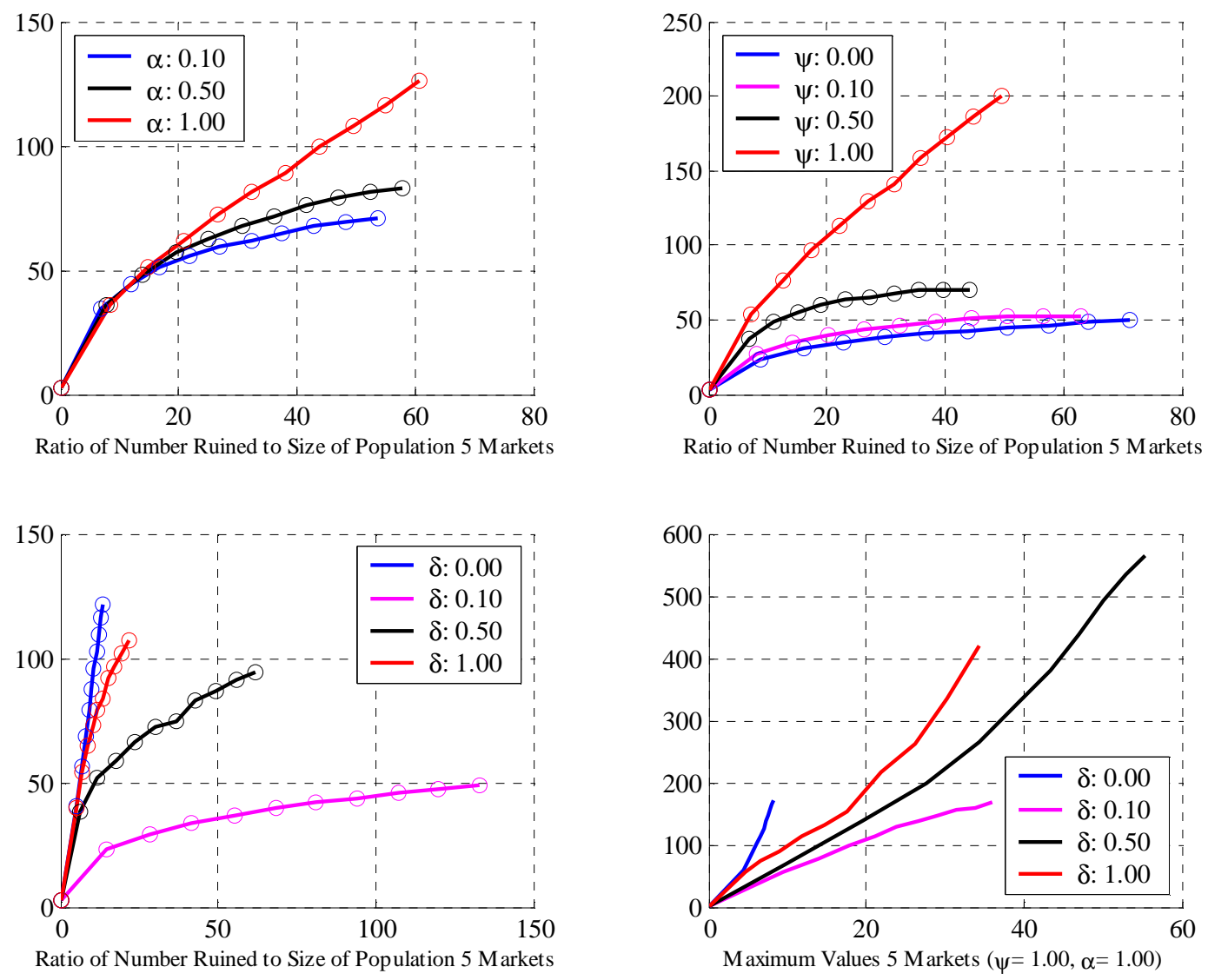


\section{Appendix 3, ctd.}

Figure 6: Ten Populations
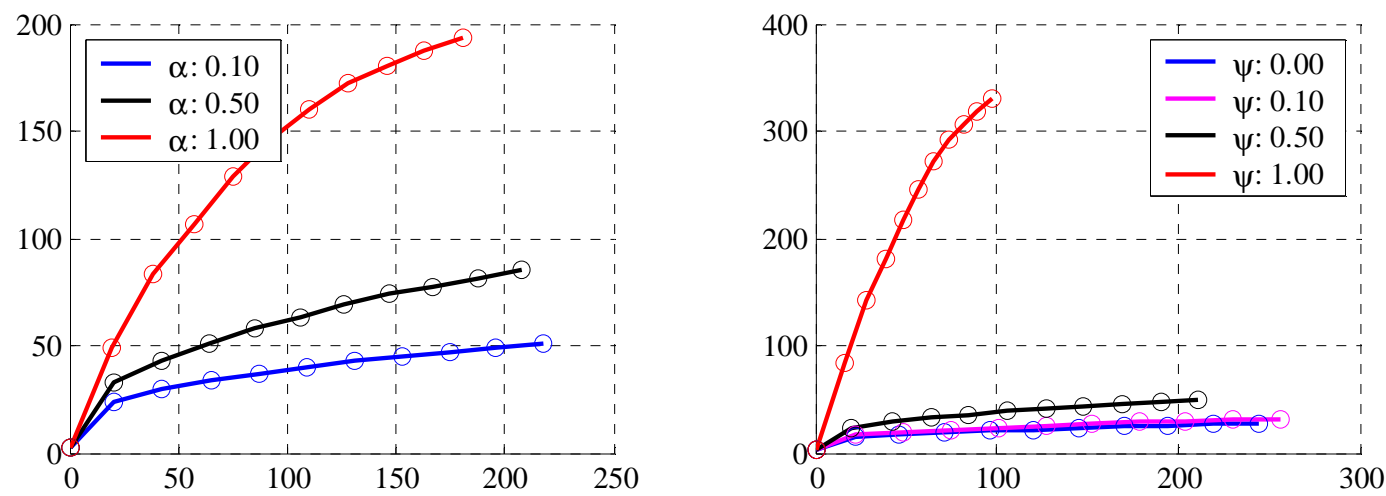

Ratio of Number Ruined to Size of Population 10 Markets

Ratio of Number Ruined to Size of Population 10 Markets
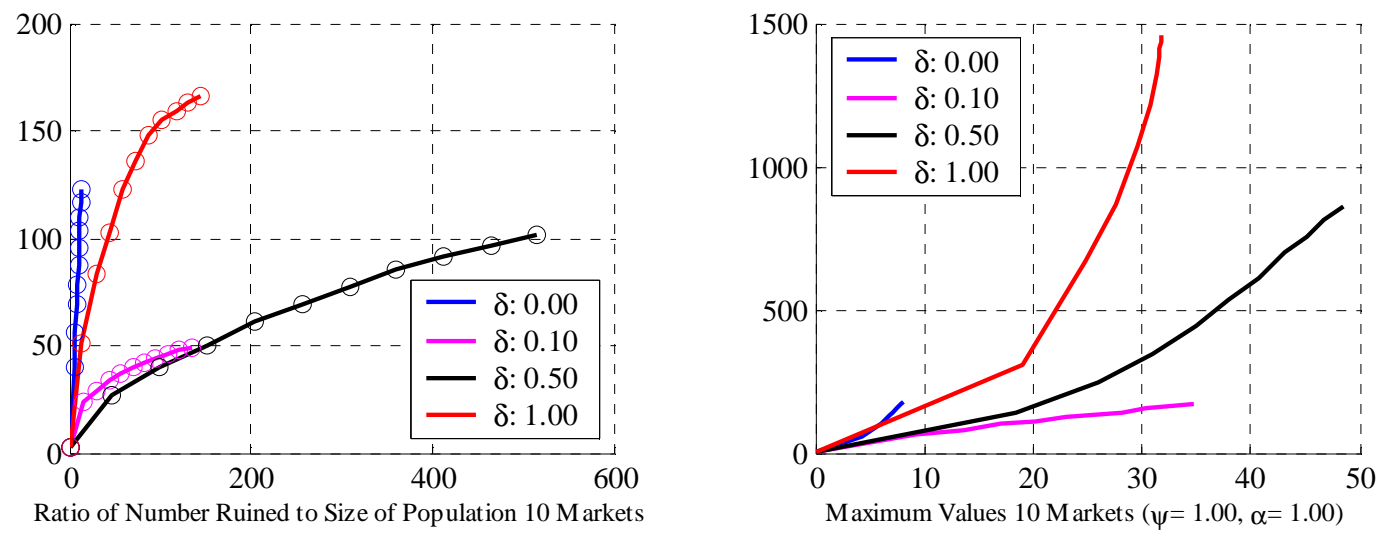